\title{
Laparoscopic versus open liver resection for hepatocellular carcinoma: initial experience in Greece
}

\author{
Georgios C. Sotiropoulos, Nikolaos Machairas, Paraskevas Stamopoulos, loannis D. Kostakis, \\ Dimitrios Dimitroulis, Dimitrios Mantas, Gregory Kouraklis
}

National and Kapodistrian University of Athens, Medical School, General Hospital Laiko, Athens, Greece

\section{Abstract}

\section{Introduction}

Hepatocellular carcinoma (HCC) represents a considerable cause of death around the world. Viral hepatitis, alcohol

$2^{\text {nd }}$ Department of Propedeutic Surgery, National and Kapodistrian University of Athens, Medical School, General Hospital Laiko, Athens, Greece

\section{Conflict of Interest: None}

Correspondence to: Georgios C. Sotiropoulos, MD, PhD, FACS, FEBS, $2^{\text {nd }}$ Department of Propedeutic Surgery, General Hospital Laiko, Ag. Thoma Str. 17, Athens 11527, Greece, Tel.: +30 210 7709948, Fax: +30 210 7709949, e-mail: georgios.sotiropoulos@uni-due.de

Received 1 April 2016; accepted 30 May 2016; published online 24 June 2016

DOI: http://dx.doi.org/10.20524/aog.2016.0067 overconsumption, metabolic disorders and a number of other causes may lead to hepatopathy and liver cirrhosis, a potentially precancerous condition, which may be complicated by the development of HCC [1]. A large part of the increasing documentation of HCC during the last decades has been attributed to the corresponding rising incidence of hepatitis $\mathrm{C}$ viral (HCV) infection [2]. Hopefully, HCV infection is going to be under control with the new anti-viral agents in the course of the forthcoming years $[3,4]$. However, the main problem in the therapeutic management of HCC remains the late diagnosis, since an important proportion of patients are not aware of their liver disease and the diagnosis of HCC comes to an advanced stage. Less than $40 \%$ of patients with first diagnosis of HCC are subject to potentially curative treatments such as liver transplantation, liver resection, or radiofrequency ablation (RFA) $[1,2]$.

Liver transplantation is the best therapy for HCC in selected patients with concrete tumor characteristics, offering 
dual management of both the tumor and the underlying liver cirrhosis [5,6]. As a consequence, post-transplant tumor recurrence is thelowest achieved by any treatment $[7,8]$. However, organ scarcity and the inappropriate tumor characteristics at diagnosis limit the widely application of liver transplantation. Expansion of the existing transplant listing criteria for HCC is considered only in some large volume transplant centers $[9,13]$. Thus, liver surgery represents the "gold standard" in the management of early or very early HCC $[1,2,14]$. Recent developments in surgical techniques, hemostatic tools and agents, anesthesia, and perioperative management made hepatic surgery feasible and safe even in patients with liver cirrhosis. However, it was only during the last 10 years, that the great evolution in laparoscopic surgery of the past 40 years was sustained in the field of liver surgery. Moreover, limited data is published on laparoscopic liver surgery for HCC in cirrhosis.

We herein report our recent institutional experience on liver resection for HCC, using laparoscopic or open technique. This series represents the first comparative study on laparoscopic versus open liver resection for HCC in Greece.

\section{Patients and methods}

Between November 2011 and February 2016, hepatic surgery was performed in 141 patients by one senior hepatobiliary surgeon (GCS) in our institution. Data from patients with HCC were prospectively implemented in a database as follow: age, gender, date of operation, etiology of liver disease, body mass index (BMI), Child-Turcotte-Pugh (CTP) score, tumor characteristics (tumor number and size, tumor satellites, vascular invasion), regional lymph node involvement, comorbidities, Milan criteria, Barcelona clinic liver cancer (BCLC) staging classification, preoperative treatment, imaging studies, and serum tumor markers. The intraoperative data recorded included type of surgery (open versus laparoscopic), type of liver resection, additional surgical procedures (cholecystectomy, lymph node biopsy, vascular reconstruction), vascular occlusion (Pringle maneuver or total vascular occlusion), blood transfusion, and total operating time. The type of surgery was decided according to the anatomical location of the HCC; scheduled resection plan; quality and volume of the remaining liver parenchyma; and recommendations of the Louisville Statement [15]. The size of the tumor per se was not a criterion for choosing between open or laparoscopic approach. Major resection was defined as resection of 3 liver segments or more. Postoperative data encompassed accomplishment (or lack thereof) of direct extubation at the end of the operation, Intensive Care Unit (ICU) treatment (if any and how long), hospital stay and 30-day mortality. The postoperative morbidity was recorded and categorized according to the Dindo-Clavien classification [16]. Histopathology documentation gathered the tumor number and size, the occurrence of tumor satellites, the presence of vascular invasion or tumor thrombi, the resection margin, the tumor differentiation [17], and the classification according to the $7^{\text {th }}$ edition of the Tumor/Node/Metastasis (TNM) and the Union for International Cancer Control (UICC) systems, respectively. Follow-up data included the current patient status, recurrent disease and treatment of recurrence and cause of death.

\section{Statistical analysis}

Continuous data were expressed as median and range values and compared by Student's $t$-test. Categorical data were compared by Fisher's exact test. Patient survival was calculated using the Kaplan-Meier method and compared with the log rank test. For the identification of prognostic factors for patient survival univariate and multivariate regression analyses were performed with the Cox proportional hazard model. Differences of $\mathrm{P}<0.05$ were considered to be statistically significant. Statistical analyses were performed using JMP (Version 8.0.2 SAS).

\section{Results}

Thirty-two patients with HCC with a median age of 65 (range 40-89) years were identified. The majority was male $(n=29)$. Etiology of liver disease was hepatitis B viral (HBV) infection $(n=17), H B V /$ hepatitis D viral infection $(n=1), H C V$ infection $(n=2)$, alcoholic liver disease (ALD, $n=3)$, nonalcoholic steatohepatitis (NASH, $n=3$ ), or combined ALD/ NASH $(n=6)$. Only one third of patients $(n=12)$ were aware of their liver disease and were followed by hepatologists. However, after the accomplishment of the diagnostic workup for the liver tumor all patients received hepatology consultation and were subsequently referred to surgery. The tumor was discovered during screening in patients with known cirrhosis (HBV-induced $n=8, H C V$-induced $n=2, A L D n=1$, ALD/NASH induced $n=1$ ), during radiological investigation of abdominal pain $(n=9)$, of weight loss $(n=2)$, of increased levels of $\gamma$-glutamyl transferase $(\gamma$-GT) $(n=4)$, or during follow up after liver resection for HCC $(n=1)$. In 4 cases, the tumor was found incidentally in the context of radiological examination of rib-fracture $(n=1)$, of follow up for neuroendocrine tumor of the lungs $(n=1)$, and of yearly sonographic checkup $(n=2)$.

Six patients underwent transarterial chemoembolization (TACE) and one combined TACE with RFA prior to surgery. Four additional patients were candidates for RFA, which could not be accomplished due to tumor localization and technical reasons. Eleven patients underwent laparoscopic and 21 open liver resection for HCC. All patients were followed up for recurrence every 3 months for the first postoperative year, every 4 months for the second, and every 6 months thereafter. No patient was lost to follow up.

\section{Patient characteristics}

Patient and tumor characteristics are demonstrated in Table 1. All but 2 patients had well preserved liver function prior to surgery, CTP score A. One patient with alcoholic liver 
Table 1 Patients' demographics, preoperative parameters and tumor characteristics

\begin{tabular}{|c|c|c|c|}
\hline Parameter & $\operatorname{LLR}(\mathrm{n}=11)$ & OLR $(n=21)$ & P-value \\
\hline Age (years) & $65(54-81)$ & $70(40-89)$ & 0.47 \\
\hline $\begin{array}{l}\text { Gender } \\
\text { Male } \\
\text { Female }\end{array}$ & $\begin{array}{l}9 \\
2\end{array}$ & $\begin{array}{c}20 \\
1\end{array}$ & 0.26 \\
\hline BMI $\left(\mathrm{kg} / \mathrm{m}^{2}\right)$ & $26(21.7-40)$ & $26.2(23-38)$ & 0.38 \\
\hline $\begin{array}{l}\text { HBV infection } \\
\text { Yes } \\
\text { No }\end{array}$ & $\begin{array}{l}7 \\
4\end{array}$ & $\begin{array}{l}10 \\
11\end{array}$ & 0.45 \\
\hline Co-morbidities & $6(1-7)$ & $5(3-9)$ & 0.14 \\
\hline $\operatorname{PLT}\left(\mathrm{x} 10^{3} / \mu \mathrm{L}\right)$ & $202(123-372)$ & $183(119-699)$ & 0.15 \\
\hline INR & $1.09(0.97-1.26)$ & $1.14(0.93-1.71)$ & 0.49 \\
\hline $\operatorname{ALT}(\mathrm{U} / \mathrm{L})$ & $23(14-54)$ & $45(9-273)$ & 0.07 \\
\hline AST (U/L) & $16(7-56)$ & $26(14-378)$ & 0.14 \\
\hline$\gamma$-GT $(\mathrm{U} / \mathrm{L})$ & $32(12-286)$ & $67(14-385)$ & 0.13 \\
\hline Bilirubin (mg/dL) & $0.73(0.26-1.39)$ & $0.63(0.42-1.35)$ & 0.49 \\
\hline Creatinine (mg/dL) & $0.75(0.6-1.1)$ & $0.9(0.54-1.6)$ & 0.28 \\
\hline Albumin (mg/dL) & $4.45(3.4-4.8)$ & $4(3.3-5.2)$ & 0.20 \\
\hline $\operatorname{AFP}(\mathrm{ng} / \mathrm{mL})$ & $7.7(1.58-43.35)$ & $25.56(2.8-1511)$ & 0.22 \\
\hline $\begin{array}{l}\text { Number of tumors } \\
\text { Solitary } \\
\text { Multifocal }\end{array}$ & $\begin{array}{c}10 \\
1\end{array}$ & $\begin{array}{c}18 \\
3\end{array}$ & 1.00 \\
\hline Size of largest tumor $(\mathrm{cm})$ & $4.7(1.8-9.7)$ & $6.1(2.5-22)$ & 0.04 \\
\hline $\begin{array}{l}\text { BCLC staging } \\
0 \\
\text { A } \\
\text { C }\end{array}$ & $\begin{array}{l}1 \\
7 \\
3\end{array}$ & $\begin{array}{c}0 \\
12 \\
9\end{array}$ & 0.29 \\
\hline $\begin{array}{l}\text { Milan criteria } \\
\text { Within } \\
\text { Out }\end{array}$ & $\begin{array}{l}6 \\
5\end{array}$ & $\begin{array}{c}6 \\
15\end{array}$ & 0.25 \\
\hline $\begin{array}{l}\text { Tumor pre-treatment } \\
\text { Yes } \\
\text { No }\end{array}$ & $\begin{array}{l}2 \\
9\end{array}$ & $\begin{array}{c}6 \\
15\end{array}$ & 0.68 \\
\hline
\end{tabular}

LLR, laparoscopic liver resection; OLR, open liver resection; BMI, body mass index; HBV infection, hepatitis B viral infection; PLT, platelets; INR, international normalized ratio; ALT, alanine aminotransferase; AST, aspartate aminotransferase; $\gamma$-GT, $\gamma$-glutamyl transferase; AFP, $\alpha$-fetoprotein; BCLC staging, Barcelona clinic liver cancer staging

cirrhosis had a history of variceal bleeding 10 years before; it was managed with successful endoscopic ligation, medical treatment with nonselective $\beta$-blockers and abstinence of alcohol, resulting in improvement in liver function to CTP A score. CTP B score was evident in 2 patients. Median values for platelets (PLT), international normalized ratio (INR), bilirubin, albumin, and creatinine were $196 \times 10^{3} / \mu \mathrm{L}, 1.12,0.69 \mathrm{mg} / \mathrm{dL}, 4.25 \mathrm{mg} / \mathrm{dL}$, and $0.87 \mathrm{mg} / \mathrm{dL}$, respectively. Median BMI and Charlson comorbidity indices were $26.05 \mathrm{~kg} / \mathrm{m}^{2}$ and 5 , respectively. Twelve patients (38\%) were meeting the Milan criteria. Median maximal tumor diameter was $9 \mathrm{~cm}$. Most patients were BCLC stage A $(n=19)$, whereas one patient was BCLC stage 0 and 12 patients BCLC stage C. Advanced BCLC stage was due to vascular invasion $(n=6)$, to performance status test 1 (strenuous physical activity restricted; fully ambulatory and able to carry out light work; $\mathrm{n}=5)$ or to both causes $(\mathrm{n}=1)$. Median $\mathrm{a}$-fetoprotein (AFP) was $8.75 \mathrm{ng} / \mathrm{mL}$. Statistical comparison of patient and tumor characteristics between patients undergoing laparoscopic or open liver resection revealed statistical difference in the size of the largest tumor $(\mathrm{P}=0.04$, Table 1$)$.

\section{Operative procedures}

Perioperative data are summarized in Table 2. Median total operating time was 180 (range 90-300) min. Liver resections included: 2 right hepatectomies, 3 left hepatectomies, one left trisectionectomy, 4 left lateral sectionectomies, one right posterior sectionectomy, 6 bisegmentectomies (segments 5/6 $\mathrm{n}=5$, segments $\mathrm{IVb} / \mathrm{V} \mathrm{n}=1$ ), 7 segmentectomies ( 5 segment VI 
resections and 2 caudate lobe resections), and one left lateral sectionectomy combined with segmentectomy and RFA. Atypical resections encompassed 4 cranial mesohepatectomies (segments IVa/VIII $\mathrm{n}=1$, segments IVa/VIII and partially IVb/V $n=1$, segments IVa/VIII and partially IVb/V and VII $\mathrm{n}=1$, and segments VII/VIII $\mathrm{n}=1$ ), one atypical right hepatectomy (segments VI/VII/VIII), and 2 wedge resections (segments VII/VIII plus segments V/VI $\mathrm{n}=1$, segments II/III plus RFA segment VII). All patients received elective surgery. Lymphadenectomy and lymph node biopsy in hepatoduodenal ligament were performed in 6 and 2 patients, respectively. Almost half of patients underwent cholecystectomy (17/32). Statistical difference between patients undergoing laparoscopic or open liver resection was found for the parameters performance of major resection $(\mathrm{P}=0.01)$, performance of Pringle maneuver $(\mathrm{P}=0.008)$, duration of Pringle maneuver $(\mathrm{P}=0.0001)$, blood transfusion $(\mathrm{P}=0.003)$, and duration of operation $(\mathrm{P}=0.004)$ (Table 2$)$.

\section{Pathology}

Pathology data are summarized in Table 3. Vascular invasion and tumor thrombi were documented in 15 (47\%) and $10(32 \%)$ patients, respectively. Lymph nodes were negative in all cases where lymphadenectomy or lymph node biopsies were performed ( $\mathrm{n}=8$ in total). Tumors were classified to UICC stages I, II, IIIA, and IIIB, in 13, 8, 5, and 6 instances, respectively. Tumor differentiation according to the Edmonson and Steiner grading system was stage I, II, III, and IV, in 5, 10, 14 , and 3 patients, respectively. Tumor-free resection margin (R0-resection) was identified in 29 of 32 patients (91\%). Liver cirrhosis was histologically documented in 20 patients (63\%). No statistical differences in pathology characteristics were assessed between patients undergoing laparoscopic or open liver resection (Table 3).

\section{Morbidity and mortality}

Direct extubation at the end of the operation was accomplished in all patients. Six patients were transferred to the ICU for postoperative monitoring. Ten patients experienced minor complications. Bile leakage and bleeding occurred in 2 and 1 patients, respectively, and were treated conservatively. One patient experienced aspiration pneumonia the $8^{\text {th }}$ postoperative day after right hepatectomy; he was re-intubated, transferred to the ICU but died the $25^{\text {th }}$ postoperative day of sepsis. Median hospital stay was 7 days. No statistical significance in postoperative outcomes between patients undergoing laparoscopic or open liver resection was identified (Table 4).

\section{Follow-up data}

Nine patients developed tumor recurrence during the postoperative follow up. In all but one patient the sites of
Table 2 Perioperative data concerning surgical details and blood transfusion

\begin{tabular}{|c|c|c|c|}
\hline Parameter & $\operatorname{LLR}(\mathrm{n}=11)$ & OLR $(n=21)$ & P-value \\
\hline Major resection & & & 0.01 \\
\hline Yes & 0 & 9 & \\
\hline No & 11 & 12 & \\
\hline \multicolumn{4}{|l|}{ Type of resection } \\
\hline Right hepatectomy & 0 & 2 & \\
\hline Left hepatectomy & 0 & 3 & \\
\hline Left trisectionectomy & 0 & 1 & \\
\hline Right posterior & 0 & 1 & \\
\hline sectionectomy & 3 & 2 & \\
\hline Left lateral sectionectomy & 4 & 2 & \\
\hline Bisegmentectomy & 4 & 3 & \\
\hline Segmentectomy & 0 & 7 & \\
\hline \multicolumn{4}{|l|}{ Others } \\
\hline Pringle maneuver & & & 0.008 \\
\hline Yes & 2 & 15 & \\
\hline No & 9 & 6 & \\
\hline $\begin{array}{l}\text { Pringle maneuver } \\
\text { duration (min) }\end{array}$ & $0(0-15)$ & $20(0-60)$ & 0.0001 \\
\hline Blood transfusion & & & 0.003 \\
\hline Yes & 4 & 19 & \\
\hline No & 7 & 2 & \\
\hline Duration of operation (min) & $120(90-180)$ & $200(90-300)$ & 0.004 \\
\hline
\end{tabular}

Table 3 Pathology results

\begin{tabular}{lccc}
\hline Parameter & $\begin{array}{c}\text { LLR } \\
(\mathrm{n}=11)\end{array}$ & $\begin{array}{c}\text { OLR } \\
(\mathrm{n}=21)\end{array}$ & P-value \\
& 3 & 12 & 0.25 \\
\hline Vascular invasion & 8 & 9 & \\
$\quad$ Yes & & & 0.11 \\
$\quad$ No & 1 & 9 & \\
Tumor thrombi & 10 & 12 & \\
Yes & & & 0.153 \\
No & 6 & 7 & \\
UICC Stage & 4 & 4 & \\
I & 1 & 4 & \\
II & 0 & 6 & \\
IIIA & & & 0.455 \\
IIIB & 1 & 4 & \\
Histological grade & 4 & 6 & \\
Well differentiated & 6 & 8 & \\
Moderately differentiated & 4 & 3 & \\
Poorly differentiated & 0.53 \\
Undifferentiated & & & \\
Resection margin & 0 & 3 & \\
Positive & 11 & 18 & \\
Negative &
\end{tabular}

$L L R$, laparoscopic liver resection; OLR, open liver resection; UICC, union for international cancer control

recurrence was the liver; the patient who developed intraand extrahepatic tumor recurrence has undergone a repeated liver resection for a multifocal stage IIIB HCC 8 months after an atypical right hepatectomy for a stage II HCC; he was 
treated with TACE and sorafenib but died 5 months after the second liver resection. TACE was the treatment of recurrence in 4 additional patients, whereas one patient underwent conventional chemotherapy. Currently 26 patients are alive after a median follow up of 18 (range 6-48) months. One-year and 3-year postoperative survival after laparoscopic and open hepatectomy was $100 \%$ and $100 \%$, and $79 \%$ and $67 \%$, respectively $(\mathrm{P}=0.06$, marginal significance, Fig. 1$)$.

\section{Prognostic factors for patient survival}

The parameters age, gender, BMI, etiology of liver disease, Charlson's comorbidity index, BCLC staging, AFP, creatinine, $\gamma$-GT, laparoscopic hepatectomy, blood transfusion, operative time, UICC stage, tumor grade, R0 resection, Dindo-Clavien classification of postoperative complications, and hospital stay were evaluated by univariate analysis. Parameters that are

Table 4 Postoperative outcomes regarding postoperative management, morbidity and mortality and oncological outcomes

\begin{tabular}{|c|c|c|c|}
\hline Parameter & $\begin{array}{c}\text { LLR } \\
(\mathrm{n}=11)\end{array}$ & $\begin{array}{c}\text { OLR } \\
(\mathrm{n}=21)\end{array}$ & P-value \\
\hline $\begin{array}{l}\text { ICU treatment } \\
\text { Yes } \\
\text { No }\end{array}$ & $\begin{array}{c}0 \\
11\end{array}$ & $\begin{array}{c}6 \\
15\end{array}$ & 0.07 \\
\hline $\begin{array}{l}\text { Complications } \\
\text { No } \\
\text { Yes }\end{array}$ & $\begin{array}{l}9 \\
2\end{array}$ & $\begin{array}{c}12 \\
9\end{array}$ & 0.25 \\
\hline $\begin{array}{l}\text { Dindo-Clavien category } \\
\text { Grade I } \\
\text { Grade II } \\
\text { Grade V }\end{array}$ & $\begin{array}{l}1 \\
1 \\
0\end{array}$ & $\begin{array}{l}0 \\
8 \\
1\end{array}$ & \\
\hline Postoperative mortality & 0 & 1 & 0.11 \\
\hline $\begin{array}{l}\text { Length of hospital } \\
\text { stay (days) }\end{array}$ & $5(4-14)$ & $8(5-25)$ & 0.09 \\
\hline $\begin{array}{l}\text { Tumor recurrence } \\
\text { Yes } \\
\text { No }\end{array}$ & $\begin{array}{c}1 \\
10\end{array}$ & $\begin{array}{c}8 \\
13\end{array}$ & 0.11 \\
\hline
\end{tabular}

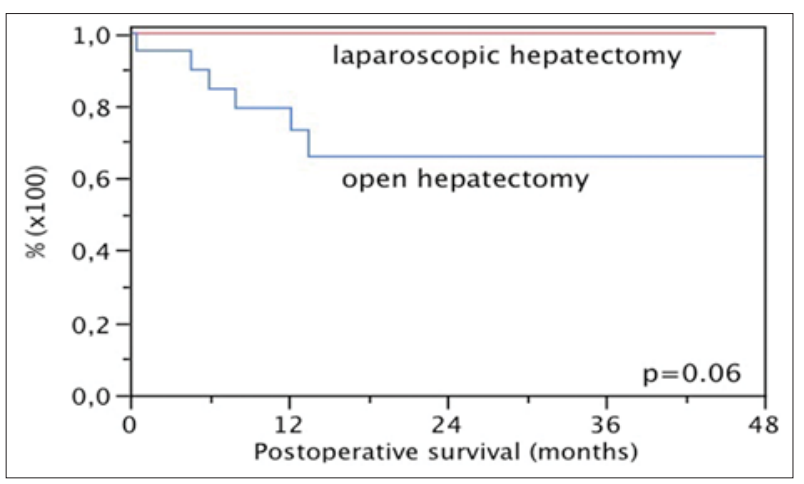

Figure 1 Kaplan-Meier patient survival analysis according to the type of hepatectomy taken into account in the BCLC staging, such as tumor number, tumor size, vascular invasion, Milan criteria, PLT count, INR, bilirubin, and albumin, were not separately assessed. BCLC staging $(\mathrm{P}=0.0177), \gamma-\mathrm{GT}(\mathrm{P}=0086)$, laparoscopic hepatectomy ( $\mathrm{P}=0.0209)$, UICC stage $(\mathrm{P}=0.008)$, Dindo-Clavien classification $(\mathrm{P}=0.0158)$, and hospital stay $(\mathrm{P}=0.0271)$, were found to be significant predictors of patient survival by univariate Cox proportional hazard regression analysis (Table 5). Since UICC stage, Dindo-Clavien classification and hospital stay are not predictable preoperatively, only BCLC staging, $\gamma$-GT, and laparoscopic hepatectomy were included in the multivariate analysis. Performance of laparoscopic hepatectomy remained as the unique independent predictor of survival by multivariate Cox proportional hazard regression analysis $(\mathrm{P}=0.0142)$.

\section{Discussion}

Although the first reports on laparoscopic liver resections were published in the early 1990s $[18,19]$, and the first laparoscopic hepatectomy for HCC in 1995 [20], for many years most hepatobiliary surgeons were very restrained regarding the performance of laparoscopic liver resections. An increasing controversy between enthusiasm and skepticism on the new technique led to the organization of the $1^{\text {st }}$ World Consensus Meeting on laparoscopic hepatectomy in 2009 [15], where indications and contra-indications for the new technique were thoroughly discussed and the pillar for the modern hepatic surgery was set. It was then, that laparoscopic hepatectomy was acknowledged as a "safe and effective approach to the management of surgical liver disease in the hands of trained surgeons with experience in hepatobiliary and laparoscopic surgery". Afterwards, a significant evolution in this field was noted, and the spectrum of laparoscopic liver resections was opened from liver biopsies and liver cysts deroofing up to typical and atypical hepatectomies for benign and malignant diseases and to live donor hemihepatectomy for transplantation [21,22]. Last achievement is the performance of laparoscopic multiple metastasectomies for colorectal liver metastases and of laparoscopic hepatectomy in the cirrhotic liver [23-25].

Some comparative studies and systematic reviews have already been published on the surgical outcomes of laparoscopic versus open liver procedures [26-28]. Among the documented benefits that a laparoscopic liver resection in comparison to the open approach might offer are the decreased blood loss and requirement for blood transfusion, the reduced operative time, the lower overall postoperative morbidity, the less postoperative pain and the shorter hospital stay [26-28]. Concerns for uncontrolled bleeding, compromised tumor margin or the port-site metastases have not been confirmed [26-28]. In addition, according to the current knowledge, patient survival and recurrence-free survival seem not to be influenced by the kind of procedure [28].

As demonstrated in recent comparative studies in Table 6, tumor size, operative time, blood loss, and hospital stay were reported between 2 and $8.5 \mathrm{~cm}, 185$ and $365 \mathrm{~min}, 80$ and $1085 \mathrm{~mL}$, and 6 and 17 days in median values, respectively. 
6 G. C. Sotiropoulos et al

Table 5 Univariate and multivariate Cox proportional hazards regression analysis for patient survival

\begin{tabular}{|c|c|c|c|}
\hline \multirow[t]{3}{*}{ Patient/tumor parameters } & & \multicolumn{2}{|c|}{$\mathrm{P}$-value } \\
\hline & & \multicolumn{2}{|c|}{ Patient survival } \\
\hline & & Univariate analysis & Multivariate analysis \\
\hline Age (years) & $65(40-89)$ & 0.7748 & \\
\hline $\begin{array}{l}\text { Gender } \\
\text { Male } \\
\text { Female }\end{array}$ & $\begin{array}{c}29 \\
3\end{array}$ & 0.2001 & \\
\hline BMI $\left(\mathrm{kg} / \mathrm{m}^{2}\right)$ & $26(21-40)$ & 0.8927 & \\
\hline $\begin{array}{l}\text { Etiology of liver disease } \\
\text { HBV } \\
\text { Other }\end{array}$ & $\begin{array}{l}17 \\
15\end{array}$ & 0.5833 & \\
\hline Co-morbidities & $5(1-9)$ & 0.2763 & \\
\hline $\begin{array}{l}\text { BCLC staging } \\
0 \\
\mathrm{~A} \\
\mathrm{C}\end{array}$ & $\begin{array}{c}1 \\
19 \\
12\end{array}$ & 0.0177 & 0.2559 \\
\hline $\operatorname{AFP}(\mathrm{ng} / \mathrm{mL})$ & $8.75(1.58-1511)$ & 0.0652 & \\
\hline Creatinine (mg/dL) & $0.87(0.54-1.6)$ & 0.4345 & \\
\hline$\gamma-\mathrm{GT}(\mathrm{U} / \mathrm{L})$ & $60(12-385)$ & 0.0086 & 0.3722 \\
\hline $\begin{array}{l}\text { Laparoscopic hepatectomy } \\
\text { Yes } \\
\text { No }\end{array}$ & $\begin{array}{l}11 \\
21\end{array}$ & 0.0209 & 0.0142 \\
\hline $\begin{array}{l}\text { Blood transfusion } \\
\text { Yes } \\
\text { No }\end{array}$ & $\begin{array}{c}23 \\
9\end{array}$ & 0.5182 & \\
\hline Operative time (min) & $180(90-300)$ & 0.1924 & \\
\hline $\begin{array}{l}\text { UICC stage } \\
\text { I } \\
\text { II } \\
\text { IIIA } \\
\text { IIIB }\end{array}$ & $\begin{array}{c}13 \\
8 \\
5 \\
6\end{array}$ & 0.008 & \\
\hline $\begin{array}{l}\text { Tumor grade } \\
\text { Well } \\
\text { Moderate } \\
\text { Poor } \\
\text { Undifferentiated }\end{array}$ & $\begin{array}{c}5 \\
10 \\
14 \\
3\end{array}$ & 0.4617 & \\
\hline $\begin{array}{l}\text { R0 resection } \\
\text { Yes } \\
\text { No }\end{array}$ & $\begin{array}{c}29 \\
3\end{array}$ & 0.0843 & \\
\hline $\begin{array}{l}\text { Dindo-Clavien category } \\
0 \\
1 \\
2 \\
5\end{array}$ & $\begin{array}{c}21 \\
1 \\
9 \\
1\end{array}$ & 0.0158 & \\
\hline Hospital-stay (days) & $7(4-25)$ & 0.0271 & \\
\hline
\end{tabular}

Data are expressed as median and range values. Statistical significant P-values are highlighted with bold characters

BMI, body mass index; HBV, hepatitis B virus; BCLC staging, Barcelona clinic liver cancer staging; AFP, $\alpha$-fetoprotein; $\gamma$-GT, $\gamma$-glutamyl transferase; UICC, union for international cancer control

Three-year patient survival was $60.7-100 \%$ and $41.8-100 \%$ for laparoscopic and open resections, respectively. In most studies, disease-free survival showed no statistical differences [29-35].
In the present series, patients with HCC undergoing laparoscopic live surgery (Fig. 2) had statistically smaller tumors $(\mathrm{P}=0.04)$ compared with patients undergoing open 
Table 6 Literature data on recent comparative studies on laparoscopic and open liver resections for hepatocellular carcinoma

\begin{tabular}{|c|c|c|c|c|c|c|c|c|}
\hline Author & Procedure & $\mathrm{N}$ & $\begin{array}{l}\text { Tumor } \\
\text { size }\end{array}$ & $\begin{array}{l}\text { Operative } \\
\text { time }\end{array}$ & Blood loss & $\begin{array}{c}\text { Hospital } \\
\text { stay }\end{array}$ & $\begin{array}{c}\text { 3-year } \\
\text { survival }\end{array}$ & DFS \\
\hline \multicolumn{9}{|c|}{ Leong, et al [28]* } \\
\hline & & 42 & & 250 & 495 & 7 & & $52 \%$ \\
\hline & open & 110 & & 349 & 1085 & 11 & & $38 \%$ \\
\hline & P-value & & & $<0.001$ & $<0.001$ & $<0.001$ & & 0.035 \\
\hline \multicolumn{9}{|c|}{ Komatsu, et al [29] } \\
\hline & & 38 & 4.7 & 365 & 100 & 7 & $73 \%$ & $50 \%$ \\
\hline & open & 38 & 8.5 & 300 & 80 & 10 & $69 \%$ & $29 \%$ \\
\hline & P-value & & 0.006 & $<0.001$ & 0.094 & 0.079 & 0.951 & 0.219 \\
\hline \multicolumn{9}{|c|}{ Meguro, et al [30] } \\
\hline & lap & 60 & 2.3 & 277 & 110 & & $83 \%$ & $43 \%$ \\
\hline & open & 200 & 3.5 & 312 & 420 & & $63 \%$ & $28 \%$ \\
\hline & P-value & & $<0.001$ & 0.001 & $<0.001$ & & 0.004 & 0.048 \\
\hline \multicolumn{9}{|c|}{ Xiao, et al [31] } \\
\hline & lap & 41 & & 242 & 272 & 9 & $78 \%$ & $70 \%$ \\
\hline & open & 86 & & 235 & 450 & 14 & $82 \%$ & $68 \%$ \\
\hline & P-value & & & 0.589 & 0.001 & $<0.001$ & 0.448 & 0.808 \\
\hline \multicolumn{9}{|c|}{ Martin RC 2nd, et al [32]* } \\
\hline & lap & 100 & 6.7 & & 336 & 6.2 & $60 \%$ & $20 \%$ \\
\hline & open & 254 & 8.5 & & 755 & 9.3 & $41 \%$ & $26 \%$ \\
\hline & P-value & & 0.07 & & $<0.001$ & 0.001 & 0.499 & 0.826 \\
\hline \multicolumn{9}{|c|}{ Kim, et al [33] } \\
\hline & lap & 70 & 2.5 & 215 & & 12 & $65 \%$ & $51 \%$ \\
\hline & open & 70 & 2.4 & 282 & & 17 & $65 \%$ & $54 \%$ \\
\hline & P-value & & 0.55 & 0.001 & & 0.44 & 0.610 & 0.773 \\
\hline \multicolumn{9}{|c|}{ Kim, et al [34] } \\
\hline & lap & 29 & 3.5 & 210 & 485 & 7 & $100 \%$ & $54 \%$ \\
\hline & open & 29 & 4.2 & 203 & 261 & 13 & $92 \%$ & $40 \%$ \\
\hline & P-value & & 0.278 & 0.681 & 0.065 & $<0.001$ & $>0.05$ & $>0.05$ \\
\hline \multicolumn{9}{|c|}{ Kobayashi, et al [35] } \\
\hline & lap & 24 & 2 & 198 & 110 & 11 & $100 \%$ & $50 \%$ \\
\hline & open & 27 & 2.2 & 185 & 450 & 17 & $100 \%$ & $62 \%$ \\
\hline & P-value & & 0.3371 & 0.7598 & 0.0019 & $<0.0001$ & & \\
\hline
\end{tabular}

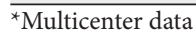

DFS, disease-free survival

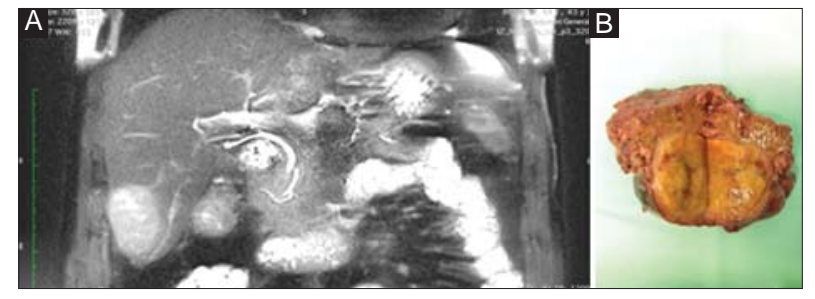

Figure 2 (A) Magnetic resonance imaging and (B) specimen, of a patient with hepatocellular carcinoma in segment VI in cirrhosis undergoing laparoscopic hepatectomy

liver surgery (Fig. 3), resulting in statistically less major resections $(\mathrm{P}=0.01)$, less requirement for Pringle maneuver $(\mathrm{P}=0.008)$ and intraoperative blood transfusion $(\mathrm{P}=0.03)$, and shorter duration of operation $(\mathrm{P}=0.004)$. Noteworthy, in all other patient and tumor characteristics, pathology results and postoperative outcomes, no statistical difference between the 2 groups was detected. Hospital stay, though shorter in the laparoscopic group (5 versus 8 days in the open group), gained only marginal significance in the present series $(\mathrm{P}=0.09)$. Three-year postoperative survival after laparoscopic and open hepatectomy was $100 \%$, and $67 \%$, respectively $(\mathrm{P}=0.06)$.

A point of discussion and criticism in our series might be the fact that $12 / 32$ patients were BCLC stage $C$ due to vascular invasion $(n=6)$, to performance status test $1(n=5)$ or to both causes $(n=1)$. BCLC algorithm proposes the first-line treatment options for patients with HCC. However, this algorithm is not binding. The heterogeneity of HCC, the modern individualized patient approach, the local institutional facilities, the fact that vascular invasion represents a contra-indication to liver transplantation but not to liver resection and the contemporary perioperative support to patients with performance status 1 are some factors that allowed us to carefully select patients with BCLC stage $\mathrm{C}$ to liver resection. Moreover, as the initiators of the BCLC system very recently underline, "several factors affect treatment of advanced stage, so that each patient with HCC 
should be carefully evaluated and treatment should be selected based on individual features" [36].

One limitation of this study was the small volume of the groups. However, data was sampled within a relative short period of time (4 years and 3 months), patients were evaluated and operated by the same senior hepatobiliary surgeon (reducing in this way the biases of patient selection for surgery, selection of operative procedure and operative technique), and this series is the first comparative study on laparoscopic versus open liver resection, regardless of indication, in Greece.
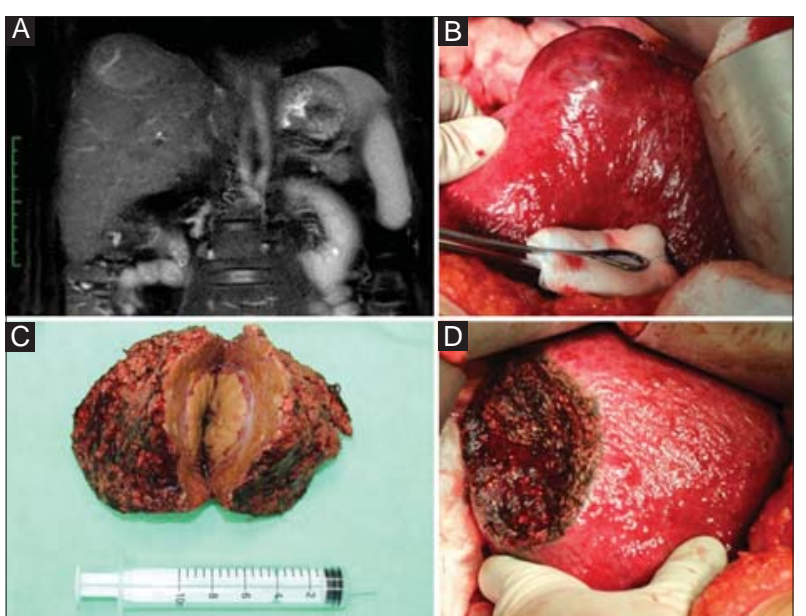

Figure 3 Magnetic resonance imaging (A), operative field before (B) and after hepatectomy (D) as well as operative specimen (C) of a patient with hepatocellular carcinoma in segment VII in cirrhosis undergoing open hepatectomy

\section{Summary Box}

\section{What is already known:}

- Liver resection is the standard of care for selected patients with hepatocellular carcinoma (HCC)

- Laparoscopic hepatectomy represents the new trend in the operative management of HCC and finds increasing application during the last decade

- Limited comparative data on open versus laparoscopic hepatectomy for HCC have been published in Europe

\section{What the new findings are:}

- First comparative study on laparoscopic versus open liver resection for HCC in Greece

- Laparoscopic hepatectomy favored intraoperative outcomes without compromising pathology and postoperative outcomes

- Laparoscopic hepatectomy was an independent predictor of patient survival by multivariate analysis
Despite the small study volume, Cox proportional hazard regression analysis for patient survival revealed 6 prognostic factors, BCLC staging, $\gamma$-GT levels, laparoscopic hepatectomy, UICC stage, Dindo-Clavien classification, and hospital stay. Laparoscopic hepatectomy remained as independent predictor of survival by multivariate Cox proportional hazard regression analysis $(\mathrm{P}=0.0142)$.

In conclusion, laparoscopic hepatectomy claims a notable proportion in the management of patients with HCC in chronic liver disease. Careful patient selection is of cardinal importance for the success of this innovative and promising method.

\section{References}

1. Jelic S, Sotiropoulos GC; ESMO Guidelines Working Group. Hepatocellular carcinoma: ESMO Clinical Practice Guidelines for diagnosis, treatment and follow-up. Ann Oncol 2010;(Suppl 5):59-64.

2. European Association For The Study Of The Liver; European Organisation For Research And Treatment Of Cancer. EASLEORTC clinical practice guidelines: management of hepatocellular carcinoma. J Hepatol 2012;56:908-943.

3. Hézode C, Chevaliez S, Scoazec G, et al. Retreatment with sofosbuvir and simeprevir of patients with HCV GT1 or 4 who previously failed a daclatasvir-containing regimen. Hepatology 2016 (in press)

4. Zopf S, Kremer AE, Neurath MF, Siebler J. Advances in hepatitis C therapy: What is the current state - what come's next? World J Hepatol 2016;8:139-147.

5. Sotiropoulos GC, Drühe N, Sgourakis G, et al. Liver transplantation, liver resection, and transarterial chemoembolization for hepatocellular carcinoma in cirrhosis: which is the best oncological approach? Dig Dis Sci 2009;54:2264-2273.

6. Sotiropoulos GC. Survival benefit in hepatocellular carcinoma: when an innovative transplant strategy might benefit oncology. Lancet Oncol 2011;12:611-612.

7. Sotiropoulos GC, Lang H, Nadalin S, et al. Liver transplantation for hepatocellular carcinoma: University Hospital Essen experience and metaanalysis of prognostic factors. J Am Coll Surg 2007;205:661-675.

8. Sotiropoulos GC, Molmenti EP, Lösch C, Beckebaum S, Broelsch CE, Lang H. Meta-analysis of tumor recurrence after liver transplantation for hepatocellular carcinoma based on 1,198 cases. Eur J Med Res 2007;12:527-534.

9. Sotiropoulos GC, Lang H, Sgourakis G, et al. Liberal policy in living donor liver transplantation for hepatocellular carcinoma: lessons learned. Dig Dis Sci 2009;54:377-384.

10. Sotiropoulos GC, Malagó M, Molmenti EP, et al. Impact of a living donor liver transplant program for hepatocellular carcinoma to the running local deceased donor liver transplant program. Dig Dis Sci 2010;55:872-873.

11. Sotiropoulos GC, Lang H, Frühauf NR, et al. Split liver transplantation for hepatocellular carcinoma. Hepatogastroenterology 2006;53:764-767.

12. Sotiropoulos GC, Paul A, Molmenti E, et al. Liver transplantation for hepatocellular carcinoma in cirrhosis within the Eurotransplant area: an additional option with "livers that nobody wants". Transplantation 2005;80:897-902.

13. Sotiropoulos GC, Molmenti EP, Lang H. Milan criteria, up-toseven criteria, and the illusion of a rescue package for patients with liver cancer. Lancet Oncol 2009;10:207-208. 
14. Sotiropoulos GC, Lang H, Frilling A, et al. Resectability of hepatocellular carcinoma: evaluation of 333 consecutive cases at a single hepatobiliary specialty center and systematic review of the literature. Hepatogastroenterology 2006;53:322-329.

15. Buell JF, Cherqui D, Geller DA, et al; World Consensus Conference on Laparoscopic Surgery. The international position on laparoscopic liver surgery: The Louisville Statement, 2008. Ann Surg 2009;250:825-830.

16. Dindo D, Demartines N, Clavien PA. Classification of surgical complications: a new proposal with evaluation in a cohort of 6336 patients and results of a survey. Ann Surg 2004;240:205-213.

17. Edmondson HA, Steiner PE. Primary carcinoma of the liver: a study of 100 cases among 48,900 necropsies. Cancer 1954;7:462-503.

18. Reich H, McGlynn F, DeCaprio J, Budin R. Laparoscopic excision of benign liver lesions. Obstet Gynecol 1991;78:956-958.

19. Gagner M, Rheault M, Dubuc J. Laparoscopic partial hepatectomy for liver tumor. Surg Endosc 1992;6:97-98.

20. Hashizume M, Takenaka K, Yanaga K, et al. Laparoscopic hepatic resection for hepatocellular carcinoma. Surg Endosc 1995;9:1289-1291.

21. Wakabayashi G, Cherqui D, Geller DA, et al. Recommendations for laparoscopic liver resection: a report from the second international consensus conference held in Morioka. Ann Surg 2015;261:619-629.

22. Sotiropoulos GC, Stamopoulos P, Charalampoudis P, Molmenti EP, Voutsarakis A, Kouraklis G. Totally laparoscopic left hepatectomy using the Torsional Ultrasonic Scalpel. World J Gastroenterol 2013;19:5929-5932.

23. Montalti R, Tomassini F, Laurent S, et al. Impact of surgical margins on overall and recurrence-free survival in parenchymalsparing laparoscopic liver resections of colorectal metastases. Surg Endosc 2015;29:2736-2747.

24. Memeo R, de'Angelis N, Compagnon P, et al. Laparoscopic vs. open liver resection for hepatocellular carcinoma of cirrhotic liver: a case-control study. World J Surg 2014;38:2919-2926.

25. Yamashita Y, Ikeda T, Kurihara T, et al. Long-term favorable surgical results of laparoscopic hepatic resection for hepatocellular carcinoma in patients with cirrhosis: a single-center experience over a 10-year period. J Am Coll Surg 2014;219:1117-1123.
26. Xiong JJ, Altaf K, Javed MA, et al. Meta-analysis of laparoscopic vs open liver resection for hepatocellular carcinoma. World $J$ Gastroenterol 2012;18:6657-6668.

27. Twaij A, Pucher PH, Sodergren MH, Gall T, Darzi A, Jiao LR. Laparoscopic vs open approach to resection of hepatocellular carcinoma in patients with known cirrhosis: systematic review and meta-analysis. World J Gastroenterol 2014;20:8274-8281.

28. Leong WQ, Ganpathi IS, Kow AW, Madhavan K, Chang SK. Comparative study and systematic review of laparoscopic liver resection for hepatocellular carcinoma. World J Hepatol 2015;7:2765-2773.

29. Komatsu S, Brustia R, Goumard C, Perdigao F, Soubrane O, Scatton O. Laparoscopic versus open major hepatectomy for hepatocellular carcinoma: a matched pair analysis. Surg Endosc 2015 (in press).

30. Meguro M, Mizuguchi T, Kawamoto M, et al. Clinical comparison of laparoscopic and open liver resection after propensity matching selection. Surgery 2015; 158:573-587.

31. Xiao L, Xiang LJ, Li JW, Chen J, Fan YD, Zheng SG. Laparoscopic versus open liver resection for hepatocellular carcinoma in posterosuperior segments. Surg Endosc 2015;29:2994-3001.

32. Martin RC $2^{\text {nd }}$, Mbah NA, St Hill R, et al. Laparoscopic versus open hepatic resection for hepatocellular carcinoma: improvement in outcomes and similar cost. World J Surg 2015;39:1519-1526.

33. Kim SJ, Jung HK, Lee DS, Yun SS, Kim HJ. The comparison of oncologic and clinical outcomes of laparoscopic liver resection for hepatocellular carcinoma. Ann Surg Treat Res 2014;86:61-67.

34. Kim H, Suh KS, Lee KW, et al. Long-term outcome of laparoscopic versus open liver resection for hepatocellular carcinoma: a casecontrolled study with propensity score matching. Surg Endosc 2014;28:950-960.

35. Kobayashi S, Nagano H, Marubashi S, et al. Hepatectomy based on the tumor hemodynamics for hepatocellular carcinoma: a comparison among the hybrid and pure laparoscopic procedures and open surgery. Surg Endosc 2013;27:610-617.

36. Bruix J, Reig M, Sherman M. Evidence-based diagnosis, staging, and treatment of patients with hepatocellular carcinoma. Gastroenterology 2016;150:835-853. 